\title{
Benign and malignant colorectal strictures in ulcerative colitis
}

\author{
V Gumaste, D B Sachar, A J Greenstein
}

\begin{abstract}
Colorectal strictures, either benign or malignant, are not uncommon in ulcerative colitis. Fifty nine of $\mathbf{1 1 5 6}$ ulcerative colitis patients $(5 \%)$ admitted to this hospital between 1959 and 1983 developed 70 separate colorectal strictures. Seventeen of the 70 strictures (24\%) proved to be malignant and the other 53 benign. Nine patients developed more than one stricture. Three principal features distinguished the 17 malignant from the 53 benign strictures in this series: (1) appearance late in the course of ulcerative colitis $(61 \%$ probability of malignancy in strictures that develop after 20 years of disease $v 0 \%$ probability in those occurring before 10 years); (2) location proximal to the splenic flexure $(86 \%$ probability of malignancy $v 47 \%$ in sigmoid, $10 \%$ in rectum, and $0 \%$ in splenic flexure and descending colon); and (3) symptomatic large bowel obstruction ( $100 \%$ probability of malignancy $v$ only $14 \%$ in the absence of obstruction or constipation). Moreover, cancer associated with strictures tends to be more advanced (76\% stage $D, 24 \% A$ and $B$ ) than that which does not produce strictures (18\% stage D, $59 \%$ A and $B$ ).
\end{abstract}

Enteric strictures are a common complication of Crohn's disease, occurring most frequently in the small bowel. Colorectal strictures are less frequent and occur in both Crohn's disease and ulcerative colitis. The occurrence of a colonic stricture in either form of inflammatory bowel disease raises the question of malignancy. In this study we have examined both benign and malignant colorectal strictures in ulcerative colitis and have compared their features.

\section{Methods}

The medical records of 1156 ulcerative colitis patients admitted to The Mount Sinai Hospital between 1959 and 1983 were reviewed retrospectively. The diagnosis of ulcerative colitis was established by recognised radiological, endoscopic, and histopathological criteria. The characteristic features were mucosal inflammation with pseudopolyps and crypt abscesses, continuity of disease, and diffuse rectal involvement at sigmoidoscopy. Exclusion criteria included small bowel disease, severe fistulas, broad fissures, and/or epithelioid granulomas. In addition, all 'indeterminate cases' were excluded from consideration.

A stricture was defined as a fixed, localised colonic narrowing; obvious polypoid lesions producing narrowing of the lumen were excluded from the study. All 1156 charts were reviewed and all cases in which a 'narrowing' or 'stricture' was noted radiologically ( $x$ ray reports were reviewed), endoscopically, or at surgery were included in the study. Colonic structures were identified in 59 patients; initially diagnosed either by barium enema (41 patients), colonoscopy (17 patients), or surgery ( 1 patient). The total number of strictures found in these patients was 70 . Strictures were classified as benign or malignant on the basis of histopathology obtained either at endoscopy or surgery.

Fifty three benign strictures were identified, the diagnosis being based on endoscopic biopsy specimens in 12 instances, surgical specimens in 27 , and on both endoscopic and surgical specimens in nine cases. In one patient with three strictures, classification as benign was based on radiological studies and in two other patients it was based on the gross endoscopic appearances. In one case of benign stricture, the endoscopic biopsy specimen was reported as being suspicious for malignancy. The surgical specimen, however, proved to be benign. All 17 strictures that turned out to be malignant were initially detected by barium enema. Among these 17 patients, five also had endoscopic biopsies; two at first had false negative biopsy specimens with malignancy found only on subsequent biopsies one month and one year later. The diagnosis of malignancy was ultimately confirmed at surgery in all but one patient, in whom the diagnosis was confirmed by the finding of malignant cells in ascitic fluid.

The cases of benign and malignant strictures were compared with regard to their age, sex, anatomical distribution, time of detection, and presenting symptoms. The malignant strictures were also compared with 76 other non-stricturing colorectal cancers in our population of patients with ulcerative colitis. The cancers were staged using the Astler-Coller, ' and the Gastrointestinal Tumour Study Group (GITSG) criteria' as follows: A - confined to the mucosa; B1 extension into the muscularis propria but without penetration through it; B2 - extension through the rectal wall without lymph node involvement; $\mathrm{Cl}$ - involvement of one to four

TABLE I Classification of colorectal stricture in ulcerative colitis

\begin{tabular}{lrr}
\hline Total no of patients & & 59 \\
No with benign strictures only: & 37 & 42 \\
No with 1 stricture & 3 & \\
No with 2 strictures & 2 & \\
No with 3 strictures & 13 & 17 \\
No with malignant strictures: & 4 & \\
$\quad$ No with 1 malignant stricture only & & 70 \\
$\quad$ No with 1 benign and 1 malignant stricture & 53 & \\
Total no of strictures: & 17 & \\
$\quad$ No of benign strictures & \\
No of malignant strictures & \\
\hline
\end{tabular}



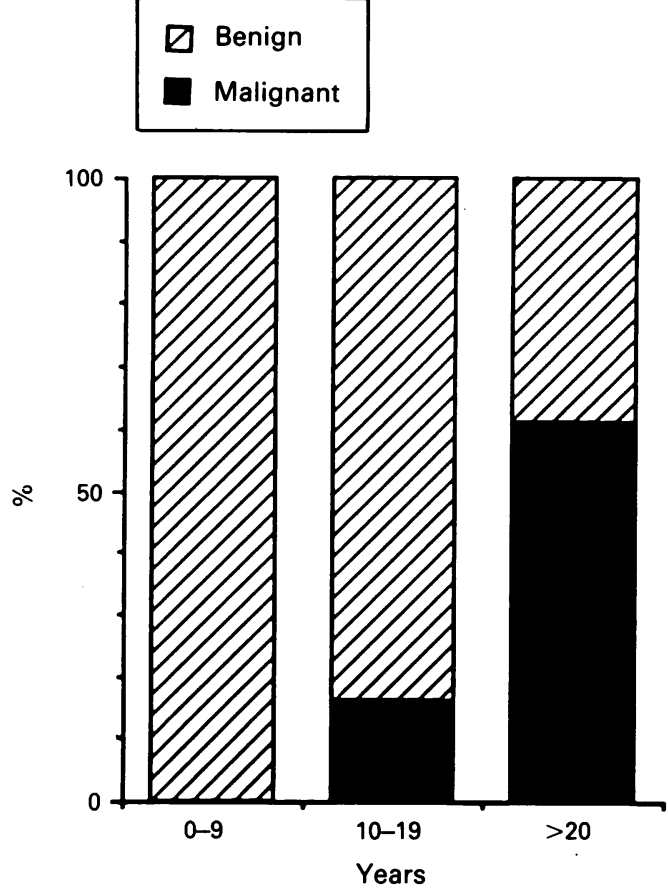

Figure 1: Proportions of benign and malignant strictures according to duration of disease. The proportion of malignant strictures increases sharply with increasing disease duration.

lymph nodes by tumour; C2 - involvement by tumour of more than four lymph nodes; D distant metastasis or unresectable invasion of adjacent organs.

Differences in ages, sex ratios, anatomical distribution of strictures, time of detection, and presenting symptoms were analysed using the $\chi^{2}$ test. The $t$ test was used to evaluate the differences between durations of disease in the two groups.

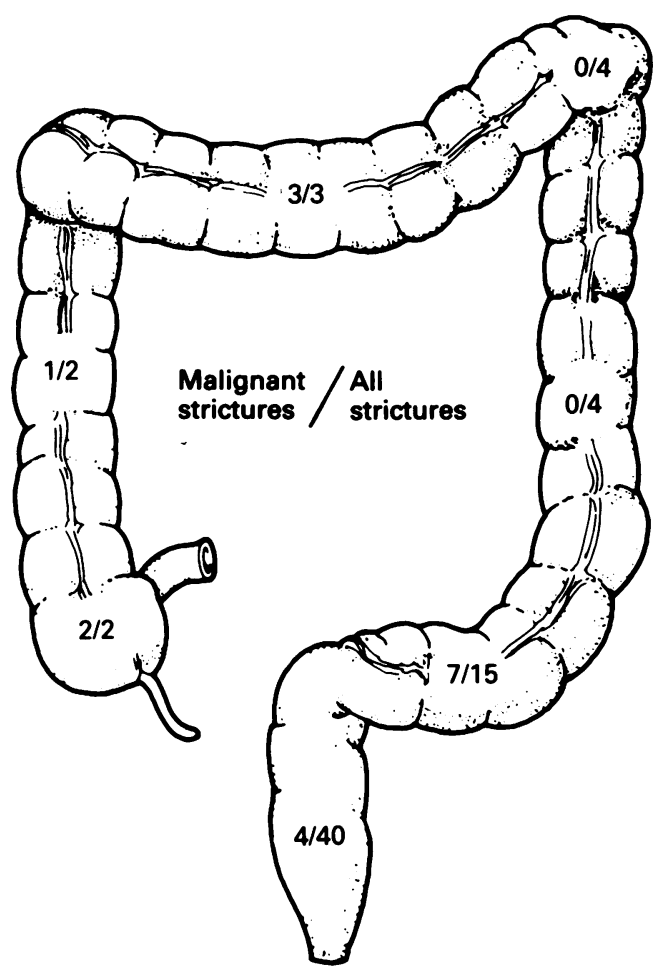

Figure 2: The anatomical distribution of strictures. Although most strictures occurred in the rectum, $90 \%$ of rectal strictures were benign whereas those few that occurred proximal to the splenic flexure were almost always (86\%) malignant.
Results

Seventy strictures were identified in 59 of 1156 ulcerative colitis patients $(5 \cdot 1 \%)$. Seventeen $(24 \%)$ of these 70 strictures were malignant while the remaining $53(76 \%)$ were benign (Table I). Nine patients had multiple strictures, and of these, four had concurrent benign and malignant lesions while the remaining five had multiple benign lesions. Although no patient had multiple malignant strictures, three of the 17 patients had one or more other sites of synchronous cancer without stricture formation.

Of the 59 patients, 31 were male and 28 female, which was similar to the male:female distribution in the total series of ulcerative colitis patients $(596: 570=52 \%: 48 \%)$. The male:female ratio in the benign group was 24:18 (4:3) and in the malignant group $7: 10$; these proportions were not significantly different.

The patients ranged in age from 14 to 76 years (mean 47) at the time of diagnosis of stricture. Among the patients with benign strictures, the mean age was 46 years (range $14-76$ years), while the mean age in the malignant group was 49 years (range 25-71 years). The mean ages of onset of colitis in the benign and malignant groups were 31 and 24 years respectively. Thus, the mean duration of colitis at the time of diagnosis of stricture was 14.5 years in the benign group (range 1.5-35 years) and 25 years in the malignant group (range 10-40 years). This difference between mean disease durations in the two groups was statistically significant $(\mathrm{p}<0 \cdot 01)$.

There were 47 patients with universal colitis and 12 patients with left sided colitis. In the malignant subset, 15 had universal colitis and two left sided colitis. Of the patients with benign strictures, 32 had universal colitis and 10 had left sided involvement alone. Sixteen per cent of the patients with left sided colitis developed malignant strictures compared with $31 \%$ of the patients with universal colitis. These differences were not statistically significant ( $p>0.05$ ).

Figure 1 shows the proportions of benign and malignant strictures by duration of colitis. All the strictures detected before 10 years of colitis were benign (12/12); from 10-19 years, $84 \%$ were benign (21/24); but at 20 years and over, most $(61 \%)$ were malignant $(14 / 23)(\mathrm{p}<0.001)$.

The anatomical distribution of strictures is presented in Figure 2. The highest probability of malignancy occurred in strictures proximal to the splenic flexure, where $6 / 7 \quad(86 \%)$ were malignant. By contrast, in the descending colon and splenic flexure, no strictures were malignant $(0 / 8)$, and in the rectum, only $10 \%(4 / 40)$ were malignant. In the sigmoid colon, however, $47 \%$ of strictures were malignant. From another point of view, six of the 17 malignant strictures occurred proximal to the splenic flexure compared with only one of 53 benign strictures $(\mathrm{p}<0.001)$.

There was a marked difference between the frequency of obstructive symptoms in benign and malignant strictures (Fig 3). Eleven of the 17 patients with malignant strictures presented with obstructive symptoms. Seven patients had one or more episodes of partial or complete large bowel obstruction and four others were constipated. Only four of the 42 patients with benign 


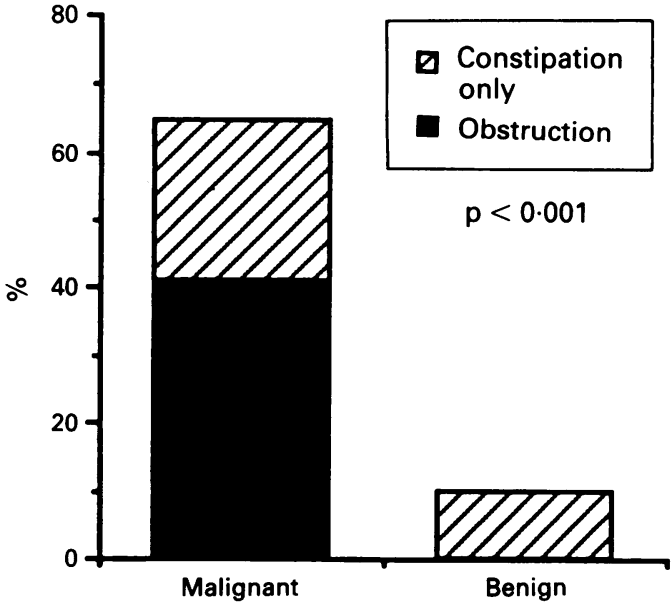

Figure 3: Frequency of obstructive symptoms in benign and malignant strictures. Obstructive symptoms were a strong predictive feature for malignancy.

strictures had constipation and none had evidence of intestinal obstruction. In other words, all patients who presented with intestinal obstruction had malignant strictures. These differences were statistically significant $(\mathrm{p}<0.001)$.

Of the 93 patients with colorectal cancer and ulcerative colitis in our total series, $17(18 \%)$ presented with a malignant stricture; the remaining 76 had polypoid, infiltrating, or ulcerating cancers without stricture formation. The histological staging of these two groups is given in Table II. Cancers associated with strictures tend to be more advanced ( $76 \%$ stages $C$ and $D$, $24 \% \mathrm{~A}$ and $\mathrm{B})$ than those that do not produce strictures (40\% stages $C$ and $D, 60 \% A$ and $B$ ) $(\mathrm{p}<0.001)$.

Twenty six of the 42 patients (61\%) with benign strictures eventually underwent surgery for medical intractability. This proportion was virtually the same as the proportion of patients coming to surgery in the entire ulcerative colitis series $(669 / 1156=58 \%)$. Of the 17 patients with malignant strictures, four had resections, 12 had palliative procedures, and one patient with an unresectable lesion was managed without surgery.

A comparison of the features of benign and malignant strictures is given in Table III. The distinguishing characteristics of malignant strictures are a longer duration to stricture formation, presentation with complete or partial large bowel obstruction, and a tendency to more proximal anatomical distribution.

\section{Discussion}

The frequency of stricture formation in ulcerative colitis varies between 3 and $10 \%$. deDombal

TABLE II Histopathological classification of malignancies in ulcerative colitis (UC) according to Dukes's classification

\begin{tabular}{llll}
\hline & $\begin{array}{l}\text { UC cancers } \\
\text { without strictures } \\
(\text { no }(\%))\end{array}$ & $\begin{array}{l}\text { UC cancers with } \\
\text { stricture cancers } \\
(\text { no }(\%))\end{array}$ & $\begin{array}{l}\text { All UC } \\
\text { with cancers } \\
(\text { no }(\%))\end{array}$ \\
\hline Stage & $13(17)$ & $1(6)$ & $14(15)$ \\
A & $32(43)$ & $3(18)$ & $35(38)$ \\
B & $17(22)$ & $0(0)$ & $17(18)$ \\
D & $14(18)$ & $13(76)$ & $27(29)$ \\
Total & 76 & 17 & 93 \\
\hline
\end{tabular}

TABLE III Differences between benign and malignant strictures occurring in ulcerative colitis

\begin{tabular}{lcl}
\hline & Benign & Malignant \\
\hline $\begin{array}{l}\text { No of patients } \\
\text { Colorectal strictures (\%) }\end{array}$ & 42 & 17 \\
Sex ratio (M:F) & $4: 3$ & 24 \\
$\begin{array}{l}\text { Mean age of onset of colitis (yrs) } \\
\begin{array}{l}\text { Mean age at diagnosis of stricture } \\
\quad \text { (yrs) }\end{array}\end{array}$ & $31 \cdot 1$ & $24 \cdot 3$ \\
$\begin{array}{l}\text { Mean duration from onset to } \\
\text { stricture formation (yrs) }\end{array}$ & $45 \cdot 6$ & $49 \cdot 2$ \\
$\begin{array}{l}\text { Usual time of detection of disease } \\
\text { (yrs) }\end{array}$ & $14 \cdot 5$ & $24 \cdot 8$ \\
$\begin{array}{c}\text { Anatomic distribution proximal } \\
\text { to splenic flexure }\end{array}$ & $<20$ & $>20$ \\
$\begin{array}{c}\text { Complete or partial large bowel } \\
\text { obstruction }\end{array}$ & Rare (2\%) & Common (35\%) \\
\hline
\end{tabular}

et $a l^{3}$ reported an $11 \cdot 2 \%$ prevalence, while Edwards and Truelove ${ }^{4}$ found strictures in $6.3 \%$ of their patients, a figure that is similar to ours $(5 \cdot 1 \%)$; Lashner et al reported a $3 \cdot 2 \%$ incidence. $^{5}$ Crohn's colitis does not differ very much from ulcerative colitis in this regard, the reported frequency of stricture being $8 \% .^{6}$

The pathogenesis of benign stricture formation in ulcerative colitis remains uncertain. Some emphasise fibrosis as the dominant feature,${ }^{78}$ but Goulston and McGovern ${ }^{9}$ indicate that contraction and hypertrophy of the muscularis mucosae are the essential features of stricture formation, and they suggest that these lesions are reversible. Indeed, Kirsner et $a l^{10}$ have reported a case of rectal stricture which reverted to normal once the symptoms had subsided.

Although the finding of a colorectal stricture in ulcerative colitis very appropriately raises concerns of cancer, all studies including our own indicate that only a minority of these strictures are in fact malignant. Seventeen of our 59 patients $(29 \%)$ had malignant strictures. Hunt $e t$ $a l^{11}$ noted only three malignancies in a total of 28 strictures in their 24 patients with ulcerative colitis, while deDombal et $a l^{3}$ failed to find a single malignant stricture in their report. However, the cancers associated with strictures in our series tended to be more advanced than those that did not cause strictures.

It is not certain whether benign strictures degenerate into malignancy or whether malignant strictures are carcinomas to start with. Previous reports have noted that $23 \%$ to $27 \%$ of colon cancers in ulcerative colitis present as strictures. ${ }^{12}{ }^{13}$ Our proportion of 17 strictures among 93 patients with colorectal cancer $(18 \%)$ is only slightly lower. In any event, the character of strictures differs dramatically between those occurring early and late in the course of the colitis. In our study, all strictures appearing in the first decade and $82 \%$ of those appearing in the first two decades of disease were benign, while most $(61 \%)$ arising after 20 years or more were malignant. In the deDombal study, ${ }^{3}$ all strictures were benign, but in $92 \%$ of patients (48 of 52) they had occurred within the first 20 years of disease; the lack of malignancy among their strictures was therefore attributable to the fact that most of their patients had disease of short duration.

The rectum was the commonest site of benign strictures, $68 \%$ in our study, as in others. ${ }^{35}$ In fact, there seems to be a general predilection of 
benign strictures for the left side of the colon. Goulston and McGovern ${ }^{7}$ found no benign strictures in the right colon among their 13 patients, leading them to speculate that a stricture on the right side is more likely to be malignant than benign. Their finding was corroborated in our series of patients. Six of the seven strictures found proximal to the splenic flexure turned out to be malignant ( $86 \%)$, in contrast to only seven of $63(11 \%)$ at or distal to the splenic flexure.

The most striking aspect of our study is the difference in presenting symptoms associated with benign $v$ malignant strictures. Eleven of the 17 patients with malignant strictures had obstructive symptoms, in sharp contrast to the benign subset of 42 patients of whom only four had constipation and none evidence of intestinal obstruction. Symptomatic obstruction with a colorectal stricture in ulcerative colitis seems therefore to be diagnostic of malignancy.

It is not possible on the basis of this retrospective analysis to make definitive recommendations for the management of strictures. However, we feel that the clinical indicators of malignancy emphasised in this study may encourage clinicians to be more aggressive, even when faced with negative endoscopic biopsy specimens. Specifically, a stricture in ulcerative colitis is more likely to be malignant (1) if it occurs after 20 years of duration of the disease, (2) if it is located proximal to the splenic flexure, and (3) if it presents with obstructive symptoms.

\section{Addendum}

Since this study was completed, two more patients with obstruction and stricture have had biopsy specimens showing adenocarcinoma in the stricture.

This work was presented at the Digestive Disease Week in Washington, DC, May 1989 and was published in abstract form (Gastroenterology 1989; 96: A189).

1 Astler VA, Coller FA. The prognostic significance of direct extension of carcinoma of the colon and rectum. Ann Surg 1954; 139: 846-52.

2 Gastrointestinal Tumor Study Group. Adjuvant therapy of colon cancer - results of a prospectively randomized trial N Englf Med 1984; 310: 737-43.

3 deDombal FT, Watts J, Watkinson G, Goligher JC. Local complications of ulcerative colitis: Stricture, pseudopoly-
posis and carcinoma of the colon and rectum. BMF 1966; 1 : 1442-7.

4 Edwards FC, Truelove SC. The course and prognosis of ulcerative colitis. Gut 1964; 5: 1-22.

5 Lashner BA, Turner BC, Bostwick DG, Frank PH, Hanaue SB. Dysplasia and cancer complicating strictures in ulceraSB. Dysplasia and cancer complicating St
tive colitis. Dig Dis Sci 1990; 34: 349-52.

6 Goldberg HI, Caruthers SB, Nelson JA, Singleton JW. Radiographic findings of the National Cooperative Crohn's Disease study. Gastroenterology 1979; 77: 925-37.

7 Lumb G, Protheroe RHB. Ulcerative colitis: a pathological study of 152 surgical specimens. Gastroenterology 1958; 34 381-407.

8 Lumb G. Pathology of ulcerative colitis. Gastroenterology 1961; 40: 290-8.

9 Goulston SJM, McGovern VJ. The nature of benign strictures in ulcerative colitis. $N$ Engl f Med 1969; 281: 290-5.

10 Kirsner JB, Palmer WL, Klotz AP. Reversibility in ulcerative colitis. Radiology 1951; 57: 1-14.

11 Hunt RH, Teague RH, Swarbrick ET, Williams CB Colonscopy in the management of colonic strictures. $B M \mathcal{F}$ Colonscopy in

12 Hinton JM. Risk of malignant change in ulcerative colitis. Gut $1966 ; 7: 426-32$

13 Greenstein AJ, Sachar DB, Pucillo, Geller SA. Cancer in universal and left-sided ulcerative colitis: Clinical and pathological features. Mt Sinai 7 Med 1979; 46: 290-8. 